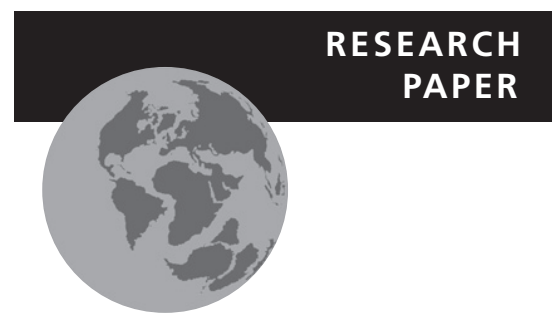

\title{
Global analysis of satellite tracking data shows that adult green turtles are significantly aggregated in Marine Protected Areas
}

Rebecca Scott ${ }^{1} \dagger$, David J. Hodgson ${ }^{1}$, Matthew J. Witt ${ }^{1}$, Michael S. Coyne ${ }^{1,2}$, Windia Adnyana ${ }^{3}$, Janice M. Blumenthal ${ }^{1,4}$, Annette C. Broderick ${ }^{1}$, Ali Fuat Canbolat ${ }^{5}$, Paulo Catry ${ }^{6}$, Stephane Ciccione ${ }^{7}$, Eric Delcroix ${ }^{8}$, Creusa Hitipeuw ${ }^{9}$, Paolo Luschi ${ }^{10}$, L. Pet-Soede ${ }^{11}$, Kellie Pendoley ${ }^{12}$, Peter B. Richardson ${ }^{1,13}$, Alan F. Rees ${ }^{1,14} \&$ Brendan J. Godley ${ }^{1 \star}$

${ }^{1}$ Centre for Ecology and Conservation, University of Exeter, Penryn, Cornwall TR10 9EZ, UK, ${ }^{2}$ Seaturtle.org, 1 Southampton Place, Durham, NC 27705, USA, ${ }^{3}$ Faculty of Veterinary Medicine, Udayana University, Kampus Bukit Jimbaran - Badung, Bali, Indonesia, ${ }^{4}$ Department of Environment, Box 486, Grand Cayman, KY1-1106 Cayman Islands, ${ }^{5}$ Department of Biology, Hacettepe University, Faculty of Science, 06532 Beytepe, Ankara, Turkey, ${ }^{6}$ Eco-ethology Research Unit and Centro de Biociências, ISPA, 1149-041 Lisboa, Portugal, ${ }^{7}$ Kelonia, 46 Rue du G. de Gaulle, 97436 Saint Leu La Reunion, ${ }^{8}$ Office National de la Chasse et de la Faune Sauvage, Cit E9 Guillard, Chemin des Bougainvilliers, 97100 Basse-Terre, Guadeloupe FWI, ${ }^{9}$ WWF-Indonesia, Kantor Taman A9, Unit A-1, Kawasan Mega Kuningan, Jakarta 12950, Indonesia, ${ }^{10}$ Dipartimento di Biologia, University of Pisa, Via A. Volta 6, I-56126 Pisa, Italy, ${ }^{11}$ World Wide Fund for Nature Coral Triangle Program Leader, Jalan Raya Petitenget 22, Kerobokan, Bali, ${ }^{12}$ Pendoley Environmental Pty Ltd, Level 1, 61 Kishorn Rd, Mt Pleasant, WA 6153, Australia,

${ }^{13}$ Marine Conservation Society, Unit 3, Wolf Business Park, Ross-on-Wye, Herefordshire HR9 5NB, UK, ${ }^{14}$ ARCHELON, The Sea Turtle Protection Society of Greece, Solomou 57, GR-104 32, Athens, Greece

${ }^{*}$ Correspondence: Brendan J. Godley, Centre for Ecology and Conservation, Tremough Campus, University of Exeter, Penryn, Cornwall TR10 9EZ, UK.

E-mail: b.j.godley@exeter.ac.uk $\dagger$ Present address: Swansea Moving Animal Research Team, Department of Biosciences, Swansea University SA2 8PP, UK.

\begin{abstract}
Aim Tracking technologies are often proposed as a method to elucidate the complex migratory life histories of migratory marine vertebrates, allowing spatially explicit threats to be identified and mitigated. We conducted a global analysis of foraging areas of adult green turtles (Chelonia mydas) subject to satellite tracking ( $n$ $=145$ ) and the conservation designation of these areas according to International Union for Conservation of Nature criteria.
\end{abstract}

Location The green turtle has a largely circumtropical distribution, with adults migrating up to thousands of kilometres between nesting beaches and foraging areas, typically in neritic seagrass or algal beds.

Methods We undertook an assessment of satellite tracking projects that followed the movements of green turtles in tropical and subtropical habitats. This approach was facilitated by the use of the Satellite Tracking and Analysis Tool (http:// www.seaturtle.org) and the integration of publicly available data on Marine Protected Areas (MPAs).

Results We show that turtles aggregate in designated MPAs far more than would be expected by chance when considered globally ( $35 \%$ of all turtles were located within MPAs) or separately by ocean basin (Atlantic $67 \%$, Indian $34 \%$, Mediterranean $19 \%$, Pacific 16\%). Furthermore, we show that the size, level of protection and time of establishment of MPAs affects the likelihood of MPAs containing foraging turtles, highlighting the importance of large, well-established reserves.

Main conclusions Our findings constitute compelling evidence of the worldwide effectiveness of extant MPAs in circumscribing important foraging habitats for a marine megavertebrate.

\section{Keywords}

Chelonia mydas, foraging, marine megavertebrate, Marine Protected Area, satellite tracking, sea turtle. 


\section{INTRODUCTION}

The current scale of the biodiversity crisis (Pimm et al., 1995; Koh et al., 2004) coupled with finite resources has provoked considerable controversy over the most legitimate goals and use of biodiversity measures to guide conservation efforts (e.g. Marris, 2007). Whilst one of the main responses has been the establishment of protected areas and ecosystem-based management approaches, this has typically focused on terrestrial biomes. Consequently the proportion of the total ocean surface currently annexed for any level of protection is an order of magnitude smaller than in the terrestrial realm (Chape et al., 2005; IUCN \& UNEP, 2010). With the ecological integrity of marine ecosystems under increasing scrutiny, and at least half of the oceans now suffering markedly from human impacts (Halpern et al., 2008), the need to redress this imbalance is becoming ever more apparent. This is particularly pertinent for coastal systems which face severe degradation in many locations due to exponentially rising human populations living in coastal areas and resultant impacts of land- and ocean-based anthropogenic activities (Green \& Short, 2003; Halpern et al., 2008; Waycott et al., 2009).

One of the most direct and pervasive threats facing marine ecosystems is the overexploitation of large marine vertebrates (Pauly et al., 1998; Pauly \& Watson, 2005). This has the potential to exacerbate the threats to these ecosystems due to the important roles large consumers are thought to play in maintaining the structure and functioning of their foraging habitats (Jackson et al., 2001; Pandolfi et al., 2003). Many sea turtle populations have been subject to high levels of harvest and other indirect threats (Jackson et al., 2001) and all species for which data are available are now of conservation concern (IUCN, 2010). The largely herbivorous green turtle (Chelonia mydas) has a circumglobal distribution in tropical and subtropical regions and after centuries of intensive harvest, some populations are recovering under increased protection (Broderick et al., 2006; Chaloupka et al., 2008).

Traditional capture, mark and recapture studies have shown how adults generally migrate hundreds to thousands of kilometres between nesting beaches and shallow neritic seagrass or algal foraging grounds (Carr et al., 1978; Balazs, 1980; Limpus et al., 1992). The recent exponential rise of satellite tracking (Godley et al., 2008) has been instrumental in detailing the routes of post-nesting migrations of marine turtle populations from nesting to foraging grounds with findings offering novel insights into basic life-history strategies as well as feeding into a number of key ecological questions considered to be important for management (Godley et al., 2008; Hamann et al., 2010). A key recurring theme is that many populations use the waters of multiple nations (Godley et al., 2008).

Nevertheless, fiscally dictated sample sizes within such studies have constrained the impact of these data, resulting in little conservation action and highlighting the need for more synthetic analytical approaches. Such analyses hold the potential to act as a strong empirical basis for assessing the efficacy of extant protected areas and highlighting key sites worthy of additional investigation and management. By conducting a global analysis of the foraging areas of green turtles tracked by satellite, integrated with data on the status, distribution and size of Marine Protected Areas (MPAs), we investigated the extent to which MPAs incorporate important foraging habitats for this species.

In light of the increasing degradation of coastal habitats, the requirements of foraging sea turtles and the role they play in maintaining the structure and functioning of seagrass habitats, we hypothesize that foraging turtles will be aggregated in MPAs where threats should be lower and habitat quality higher. Furthermore, if extant MPAs effectively circumscribe foraging sea turtles we hypothesize that turtle distribution within MPAs will be positively influenced by the size and level of protection of MPAs.

\section{MATERIALS AND METHODS}

\section{Spatial footprint of satellite tracking projects}

A global database of the deployment and foraging areas of adult green turtles tracked by satellite from breeding to neritic foraging grounds was compiled through an exhaustive review of all peer- and non-peer-reviewed literature and collaboration with colleagues who enabled unpublished satellite telemetry data to be used (see Table S1 in Supporting Information). All turtles were tracked using the Argos system operated by CLS Argos (http://www.argos-system.org); the dominant platform for following large-scale movements of marine vertebrates. In conducting this review a total of six electronic literature databases were searched (Google Scholar, Scopus, ISI Web of Science, Science Direct, Seaturtle.org and the Marine Turtle Newsletter). All searches used the following search terms: satellite tracking, sea turtle, marine turtle, green turtle, Chelonia mydas, migration and foraging. No restrictions on year of publication were imposed. The Satellite Tracking and Analysis Tool (Coyne \& Godley, 2005) facilitated collaboration among co-authors to enable both published and unpublished data to be used.

Longitude and latitude of the nesting (satellite transmitter deployment location) and final foraging areas of all postnesting/breeding adult green turtles successfully tracked to coastal foraging areas were derived from Argos locations prefiltered for accuracy using standard data filtering protocols (see, for example, Blumenthal et al., 2006). Coordinates were plotted as global point shapefiles using the World Geodetic System (1984) in ESRI ARCGIS ${ }^{\circledR}$ (version 9.2) software. The foraging areas of green turtles are typically hundreds of kilometres distant from breeding grounds. Only turtles where the final locations of tracks showed a period of residence, typically weeks or months, to coastal areas were considered successfully tracked to foraging areas. Both sexes were included in analyses as males tracked from breeding grounds have been shown to display migration patterns broadly similar to female conspecifics (Godley et al., 2008). Where individual turtles were tracked on more than one occasion or used in more than one publication (e.g. Cheng, 2000; Blumenthal et al., 2006; Broderick et al., 2007) data from the first year of tracking/publication were used. 


\section{Designation of turtle foraging areas}

The freely available World database on protected areas (www. protectedplanet.net), a global shapefile of International Union for Conservation of Nature (IUCN) designated MPAs (IUCN \& UNEP-WCMC, 2010), was used to identify which green turtle foraging areas were observed to coincide within the boundaries of MPAs and the level of protection afforded to such areas. IUCN designation ranged from category Ia (strictly protected areas managed mainly for science) to category VI (managed resource protected areas managed mainly for sustainable use; IUCN, 1994). We needed to delineate the area of sea covered by our tracking studies to evaluate how much potential habitat within each population range was designated as an MPA. Consequently for each population where the foraging areas and coastal migratory paths of three or more turtles were known, nesting locations and coastal phases of migratory routes to foraging areas were used to create minimum convex polygons (MCP; shapefiles representative of population distributional ranges, see Fig. S1) using the Geospatial Modelling Environment (Beyer, 2009). For populations with fewer than three individuals successfully tracked to foraging areas insufficient information was available to generate distributional ranges. Terrestrial area was removed from all MCP shapefiles to represent the distribution range (area) of each population. Using global bathymetry data (Amante \& Eakins, 2008), the foraging areas of all turtles were identified as occurring within water $\leq 25 \mathrm{~m}$ deep (from hereafter referred to as shallow neritic water). Within each distribution shapefile the amount of shallow neritic water and the proportion currently designated as protected along with the level of protection afforded to each MPA were then determined. Without access to all the raw satellite tracking data, MCP shapefiles were derived where necessary from digitization of nesting locations, key points of the route and the final foraging location of each turtle.

R software (R Development Core Team, 2009) was used for all statistical analyses. For our analysis we are looking at the proportion of migratory endpoints; discrete areas where turtles remained for prolonged periods (typically several weeks or months) in protected habitats. Binomial tests were used to test the null hypothesis that the proportion of turtles found to forage in designated MPAs was equal to the proportion of neritic water used by sea turtles in each ocean basin designated as an MPA. Significant departures from this null hypothesis would suggest either that foraging turtles avoid MPAs or that they are found aggregated within them. Similarly the proportion of turtles found to be foraging in MPAs was compared using binomial and goodness of fit tests among different IUCN categories of MPA protection. Significant departure from the null hypothesis of random representation of turtles among IUCN categories would denote bias in the relative quality of the categories as marine turtle foraging grounds. Due to the sensitivity of statistical analyses to sample sizes this analysis was carried out at global and regional scales, ensuring areas where the spatial footprints of populations overlapped were not counted more than once. All shapefiles were projected using the World Equidistant Cylindrical projection.

\section{Turtle aggregations in MPAs}

For individual MPAs that contained turtles, the total area of the MPA of depth $\leq 25 \mathrm{~m}$ (including the area outside turtle distributional MCPs) was also calculated. Generalized linear mixed modelling (GLMM) was then used to test whether the density of foraging turtles in each MPA was influenced by the neritic area of the MPA. The number of turtles per MPA was modelled using a Poisson error structure, regressed against the fixed effect of log-transformed neritic MPA area $\left(\mathrm{km}^{2}\right)$, meanwhile absorbing the random effect of ocean basin to control for spatial nonindependence and varying numbers of tracked turtles in each basin. MPAs in the Mediterranean were excluded due to the paucity of MPAs in this region. Year of establishment was also included as a fixed effect with the oldest MPA (designated in 1889 ) set to zero and other MPAs set to the year of establishment minus 1889. Significance of MPA area and time since establishment was tested using model simplification of a maximum likelihood version of the mixed model, followed by a likelihood ratio test (Crawley, 2007). Recognizing that turtle counts were bounded above by the total number of tracked turtles observed to forage in MPAs in each ocean basin (which violates the assumption of unbounded counts for Poisson analysis), the significance of the likelihood ratio test statistic was checked using simulations. In each simulation, turtles were assigned to MPAs at random, the GLMM test was repeated and the slope of the relationship between turtle density and MPA area and year was recorded. This process was repeated 100,000 times to achieve an empirical frequency distribution of slopes. The true slope was deemed to be significant if it lay within the top or bottom $2.5 \%$ of simulated slope magnitudes. This was conducted at a global scale whilst including ocean basin as a random effect. Regional ocean boundaries were defined by the Food and Agriculture Organization of the United Nations (FAO) major statistical areas for fishery purposes (FAO, 1990).

\section{RESULTS}

\section{Spatial footprint of satellite tracking projects}

Data were obtained for a total of 145 green turtles satellite tracked from 28 nesting sites to neritic foraging grounds (Table S1, Appendix S1). Coverage was global and included data from 11 rookeries in the Pacific, 7 rookeries in each of the Atlantic and Indian Oceans and 3 in the Mediterranean. The number of individuals successfully tracked to foraging areas ranged from a minimum of 1 (Spring, 1999; Rees et al., 2008) to 19 individuals (Kennett et al., 2004) per rookery.

\section{Effectiveness of MPAs in incorporating turtle foraging areas}

For the 116 individuals that could be used for statistical and spatial analysis ( $n \geq 3$ per population; Table S1), a total of $35 \%$ of satellite tracked green turtles were tracked to foraging areas within MPAs of varying degrees of protection. All bar two of 
Table 1 Green turtles foraging in Marine Protected Areas (MPAs). The number of turtles successfully tracked from each nesting to foraging areas $(n)$ are listed, along with the percentage of individuals in each population observed foraging in MPAs and the percentage of individuals expected to forage in MPAs assuming this corresponds to the proportion of area protected in waters $\leq 25 \mathrm{~m}$ deep used by populations.

\begin{tabular}{|c|c|c|c|c|}
\hline Ocean basin & Nesting location & $n$ & $\begin{array}{l}\text { Turtles } \\
\text { observed } \\
\text { in MPAs } \\
(\%)\end{array}$ & $\begin{array}{l}\text { Turtles } \\
\text { expected in } \\
\text { MPAs (\%) }\end{array}$ \\
\hline \multirow[t]{7}{*}{ Atlantic } & Ascension & 7 & 29 & 6 \\
\hline & Cayman & 8 & 63 & 19 \\
\hline & Costa Rica & 10 & 90 & 19 \\
\hline & Guadeloupe & 4 & 50 & 7 \\
\hline & Guinea Bissau & 4 & 100 & 26 \\
\hline & Mexico $^{*}$ & 2 & 100 & n.a. \\
\hline & Montserrat ${ }^{*}$ & 1 & 0 & n.a. \\
\hline \multirow[t]{7}{*}{ Indian } & $\begin{array}{l}\text { Australia } \\
\quad \text { (Barrow Island) }\end{array}$ & 5 & 40 & 21 \\
\hline & Australia (Scott Reef) & 3 & 1 & 1 \\
\hline & Cocos Islands & 6 & 0 & 0 \\
\hline & East Java $^{\star}$ & 2 & 0 & 0 \\
\hline & Mayotte Island & 5 & 40 & 25 \\
\hline & Sri Lanka & 9 & 44 & 15 \\
\hline & Thailand & 7 & 43 & 14 \\
\hline \multirow[t]{3}{*}{ Mediterranean } & Cyprus & 10 & 20 & 1 \\
\hline & Syria $^{*}$ & 1 & 0 & n.a. \\
\hline & Turkey & 6 & 17 & 3 \\
\hline \multirow[t]{11}{*}{ Pacific } & America Samoa & 5 & 0 & 0 \\
\hline & Australia $(\mathrm{GBR})^{*}$ & 1 & 0 & n.a. \\
\hline & China & 3 & 33 & 2 \\
\hline & French Frigate Shoals & 8 & 25 & 76 \\
\hline & Galapagos & 3 & 33 & 18 \\
\hline & Japan & 3 & 33 & 27 \\
\hline & Malaysia & 4 & 0 & 0 \\
\hline & Northern Australia ${ }^{*}$ & 19 & 0 & n.a. \\
\hline & Sangalaki* & 1 & 0 & n.a. \\
\hline & SW islands of Palau* & 2 & 50 & n.a. \\
\hline & Taiwan & 6 & 0 & 0 \\
\hline
\end{tabular}

${ }^{\star}$ Populations marked with asterisks denote populations where the foraging areas and migratory paths for fewer than three individuals were available and thus spatial and statistical analysis were not carried out. GBR, Great Barrier Reef.

these MPAs (containing one turtle each) were known to be extant at the time of tracking (Table S2). The total proportion of satellite-tracked green turtles observed foraging in MPAs was significantly greater, as much as eight-fold, than expected by chance when considered globally or when considering the Atlantic, Indian, Pacific or Mediterranean separately (Table 1, Fig. 1). We repeated binomial tests of observed and expected numbers of turtles in MPAs excluding turtles foraging in MPAs $<50 \mathrm{~km}^{2}$. Results were still significant globally $(P<0.001)$ and for all ocean basins bar the Indian which was non-significant (Atlantic $P<0.001$, Indian $P=0.122$, Mediterranean $P=0.005$, Pacific $P=0.042)$.

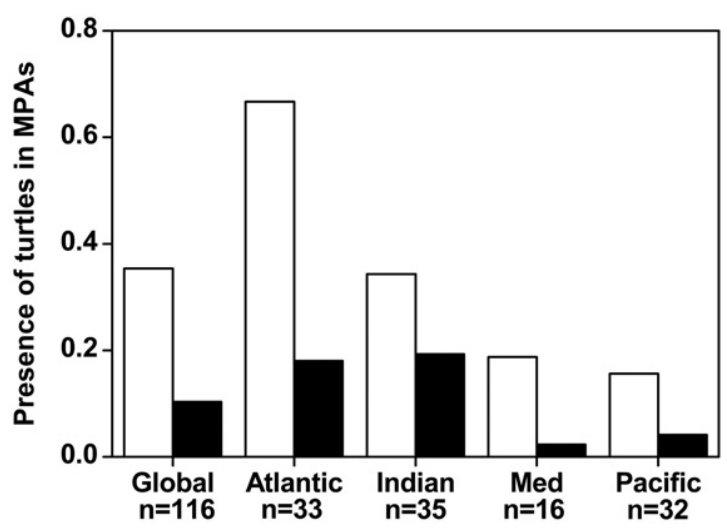

Figure 1 Effectiveness of the location of International Union for Conservation of Nature (IUCN) Marine Protected Areas (MPAs) in capturing foraging turtle locations: Observed (white bars) and expected (black bars) proportions of turtles foraging in MPAs assuming expected values correspond to the proportion of area protected in waters $\leq 25 \mathrm{~m}$ deep used by populations. The total number of turtles tracked to foraging areas are plotted below each data pair. Significantly more turtles were observed to be foraging in MPAs than expected at both global and regional scales for all ocean basins (global $P<0.001$, Atlantic $P<0.001$, Indian $P=$ 0.026 , Mediterranean $P=0.005$, Pacific $P=0.010$ ).

Whilst the proportion of green turtles foraging within the boundaries of MPAs varied greatly across ocean basins (Atlantic $67 \%$, Indian 34\%, Mediterranean 19\%, Pacific 16\%; Fig. 1), 21\% of the turtles observed to be foraging in MPAs were shown to be foraging in the most strictly protected MPAs. Where year of MPA designation was known, all bar one of these MPAs (which contained just one turtle) were designated at the time of tracking with IUCN category Ia; strictly protected areas managed mainly for science (IUCN, 1994; Fig. 2a). More turtles were tracked to category Ia MPAs, and fewer to unclassified MPAs and those known to be receiving the lowest level of protection (category VI), than was expected according to the relative areas of MPAs in these categories (Fig. 2b). A goodness of fit test revealed the bias in distribution to be significant with overrepresentation of turtles in category Ia MPAs and underrepresentation of turtles in category VI and unset MPAs $\left(\chi^{2}{ }_{5}=\right.$ 29.7, $P=0.002)$. This bias in distribution was also significant when turtles in MPAs of unset IUCN designation were excluded $\left(\chi_{4}^{2}=21.3, P=0.005\right)$.

\section{Density of turtle aggregations in MPAs}

Mixed model regression of turtle counts in MPAs against neritic surface area of MPAs revealed a highly significant positive impact of neritic MPA area on number of turtles (likelihood ratio test, $\chi^{2}{ }_{1}=121.3, P<0.001$; Fig. 3 ). This was still significant when neritic MPA areas $>4000 \mathrm{~km}^{2}$ were removed from the analysis $\left(\chi_{1}^{2}=131.4, P<0.001\right.$; Table S2). Furthermore mixed model regressions revealed that over and above the effect of MPA size, year of MPA designation also had an influence with 

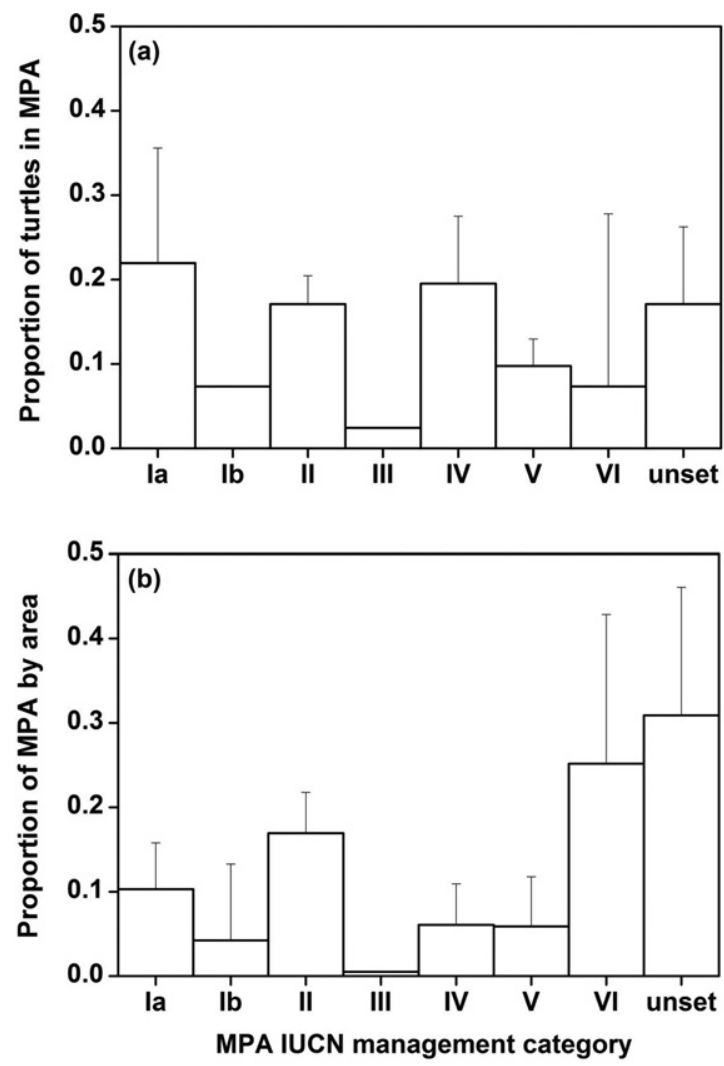

Figure 2 Effectiveness of Marine Protected Area (MPA) level of protection in capturing foraging turtle locations. (a) Proportion of turtles foraging within each management category of International Union for Conservation of Nature (IUCN) designated MPAs: (Ia) Strictly Protected Areas, managed mainly for science; (II) National Park, protected area managed mainly for ecosystem protection and recreation; (III) Natural Monument, protected area managed mainly for conservation of specific natural features; (IV) Habitat/Species Management Area, protected area managed mainly for conservation through management intervention; (V) Protected Landscape/Seascape, protected area managed mainly for landscape/seascape conservation and recreation; (VI) Managed Resource Protected Area, protected area managed mainly for the sustainable use of natural ecosystems; unset, IUCN protected area but management designation currently unset. (b) Proportion of MPAs in neritic seas used by turtles afforded each IUCN management category status. Significantly more turtles were found in category Ia MPAs than expected by chance (binomial test of observed proportion of 0.220 versus expected proportion of $0.103, n=41, P=0.022$ ), and a goodness of fit test revealed the bias in distribution to be significant with over-representation of turtles in category Ia and also IV MPAs and under-representation of turtles in unset and VI category MPAs $\left(\chi_{4}^{2}=36.4, P=0.002\right)$. Error bars of the standard error associated with ocean basins are also plotted.

more turtles aggregating in older protected areas $\left(\chi^{2}{ }_{1}=3.7, P=\right.$ 0.05). In all cases, the observed slopes lay well above the 99.9th percentile of a distribution of simulated slopes resulting from random allocation of turtles to MPAs.

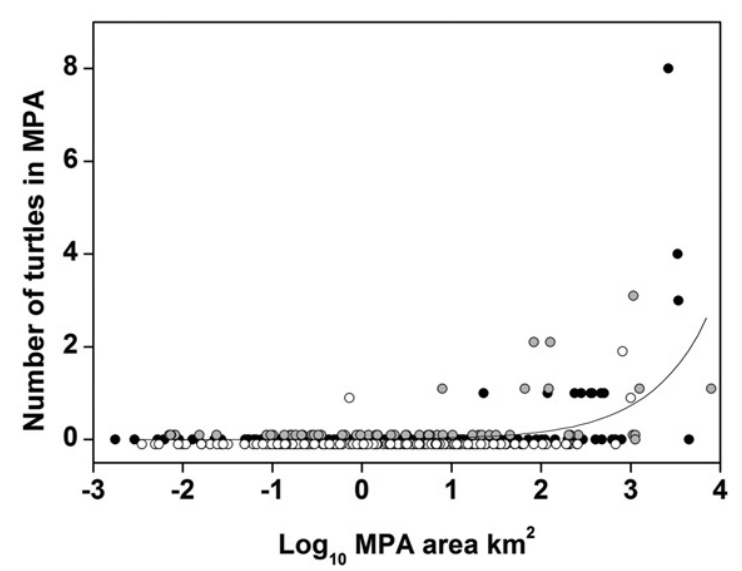

Figure 3 Relationship between the size of sea turtle foraging aggregations and the size of Marine Protected Areas (MPAs) $\leq$ $25 \mathrm{~m}$ in depth. Mixed model regression of turtle counts in MPAs against logged neritic areas of MPAs revealed a highly significant positive impact of MPA area on turtle density (likelihood ratio test, $\left.\chi_{1}^{2}=112.3, P<0.001\right)$. For graphical purposes, data are jittered and shaded to separate ocean basins (Atlantic, Black; Indian, Grey; Pacific, White) and the regression line is fitted from the mixed effect model with basin as a random effect.

\section{DISCUSSION}

World-wide concern over the status of large marine vertebrates and tropical coastal ecosystems (Jackson et al., 2001; Green \& Short, 2003; Paddack et al., 2009) has highlighted an urgent need for innovative approaches to guide marine conservation efforts (Pimm et al., 1995; Koh et al., 2004; Chape et al., 2005; Marris, 2007). The recent rise in the satellite tracking of marine vertebrates (Coyne \& Godley, 2005; Godley et al., 2008) now permits us to advance from qualitative studies of their migratory feats to inter-disciplinary analytical approaches such as the current work where data on spatial ecology are integrated with those on the status of marine habitats. Although past capture-mark-recapture data, typically concentrated at nesting sites, were instrumental in gaining insights into the long-distance migrations of sea turtles, findings are of limited spatial utility (Godley et al., 2003). In particular, distributional ranges cannot be reliably determined from these data as migration routes are unknown and recapture sites are likely to be biased to locations where there are interacting fisheries and/or focused research. Finally, with no information on residency, it is not possible to confirm whether turtles have completed migrations. The use of satellite tracking data is, however, a less biased means of reliably determining the range of foraging areas. Whilst many satellite tags are deployed on turtles at protected nesting grounds, they generally migrate considerable distances away from such areas, often in a number of range states across a region.

Notwithstanding limitations in the satellite tracking data currently available, results clearly show that foraging adult green turtles are found in association with MPAs far more often than 
expected by chance. The reasons for this correlation are not clear, but there are two obvious possibilities, which are challenging to tease apart:

1. MPAs are designated because they contain sea turtles or their important coastal habitats. Whilst turtles have indeed influenced the establishment of protected areas this has been biased towards terrestrial nesting habitats (Eckert \& Hemphill, 2005; Dobbs et al., 2007; Dryden et al., 2008) and the presence of turtles in marine areas distant from nesting habitats as a primary driver of designation is rare. The general importance of seagrasses, a primary diet item of sea turtles, is, however, widely recognized (Waycott et al., 2009) and incorporation of this habitat type may have an influence in increasing the likelihood of the presence of turtles in a MPA. However, compared with other coastal systems such as coral reefs and mangroves, sea grass habitats are deemed to be poorly represented in MPAs (Green \& Short, 2003).

2. Turtles aggregate in higher-quality habitats where threats are low. Sea turtles require healthy coastal foraging habitats and are thought to play important roles in maintaining ecosystem health (Jackson, 1997; Jackson et al., 2001). We might reasonably expect MPAs to be in better health than other areas of coastal seas and thus a better/safer habitat for exploited species, especially if there is a positive feedback loop with these large consumers maintaining habitat quality.

Irrespective of the primary underlying cause, our study is the first to provide compelling evidence as to the world-wide effectiveness of extant MPAs in capturing important foraging habitats for large marine vertebrates. Thus, we suggest that the foraging areas of such tracked animals could be used as indicators of additional habitats worthy of protection. Our rationale here is that since large animals such as green turtles are among the first to be overharvested in tropical coastal systems (Jackson et al., 2001), areas where they still persist may be excellent targets for conservation focus. This role is augmented by the fact that from a central breeding site, individuals can be tracked across a wide region, highlighting distant areas of relatively intact tropical coastal ecosystems that may not yet have been subject to over-exploitation or other forms of degradation.

Despite recent debate over the relative effectiveness of MPAs (Roberts et al., 2003; Bellwood et al., 2004; McClanahan et al., 2006; Dobbs et al., 2007; Dryden et al., 2008), it is encouraging that MPAs appear to incorporate important green turtle foraging habitats (to varying degrees) in all ocean basins. Furthermore, the finding that the size and age of MPAs significantly affects the density of sea turtle foraging aggregations underlines the importance of large and well-established reserves for large consumers and supports concerns over the small size of many reserves (Woodroffe \& Ginsberg, 1998; Carr et al., 2003; Halpern, 2003). It is also noteworthy that $21 \%$ of the turtles observed to be foraging in MPAs were shown to be foraging within the boundaries of the most strictly protected IUCN category Ia MPAs (Fig. 2a, Table S2). Large marine vertebrates face particularly high risks from anthropogenic activities in their foraging habitats (Hooker \& Gerber, 2004). Conse- quently, conservation efforts within foraging areas of sentinel species are likely to be a valuable tool in uniting single-species and ecosystem management approaches. The satellite tracking of species such as sea turtles may thus have the potential to help indicate global patterns/changes in the quality of coastal marine ecosystems and highlight important marine areas that could be priority candidates for active management. This role is anticipated to be substantiated due to the fact sea turtles show high fidelity to foraging habitats over considerable time frames (Broderick et al., 2007) and typically only return to breeding grounds every 2-7 years (Troëng \& Chaloupka, 2007).

The Argos system is currently the platform of choice for detailing the post-nesting migrations of sea turtles. Although limitations in position accuracy and frequency make it difficult to interpret fine-scale behaviour (Witt et al., 2010), concurrent GPS tracking has shown that locations of foraging areas are robust. For green turtles, core foraging areas, are typically much smaller in size than the majority of MPAs to which turtles were tracked (e.g. Seminoff et al., 2002, Troëng et al., 2005, Broderick et al., 2007; Hazel, 2009; Godley et al., 2010). The majority $(81 \%)$ of MPAs containing foraging turtles were $\left(>50 \mathrm{~km}^{2}\right)$ and when we excluded MPAs smaller than this threshold, observed numbers of turtles in MPAs were still significantly higher than expected globally and for all ocean basins bar the Indian Ocean. Small home range size, site fidelity, long breeding intervals and the size of MPAs to which the majority of turtles were tracked adds confidence in our findings that foraging green turtles are both aggregated in MPAs and likely to remain at these sites for extended periods. Given tracking duration on the foraging grounds has typically been limited (reviewed by Hays et al., 2007 although see Broderick et al., 2007) we cannot tell how site fidelity varies among individuals and populations, though as transmitters become more robust and accurate, more detailed quantitative analyses of the proportion of time spent in strictly protected areas will be possible. Due to limitations in the location accuracy of both Argos positions and protected area shapefiles, we acknowledge that the foraging locations of some turtles may have been incorrectly assigned as being within or outside of the boundaries of MPAs, however the level of significance of our results provides confidence in the robustness of our findings.

Given that the average cost of operational management of MPAs is estimated at a mere fraction of the value of coastal ecosystems (Balmford et al., 2004) the underexploited potential for charismatic sentinel species to influence conservation policy may be profound. Consequently our findings are expected to have much broader application amongst the wider marine conservation community. In addition to sea turtles, satellite tracking efforts for other candidate species such as marine mammals (Andrews et al., 2008; Edrén et al., 2010), seabirds (Boersma et al., 2007; Votier et al., 2011), sharks (Schmidt et al., 2009; Brunnschweiler et al., 2010), and other large pelagic fish (Block et al., 2003; Dewer et al., 2010) will allow for increased coverage and potential to influence conservation policy in more temperate and polar seas. 


\section{ACKNOWLEDGEMENTS}

R.S was initially funded through a Master's scholarship from the University of Exeter and currently through a NERC PhD studentship awarded to the University of Swansea. B.J.G. and A.C.B. are funded by the Darwin Initiative, European Social Fund, Natural Environment Research Council and Southwest Regional Development Agency. M.J.W. by the Peninsula Research Institute for Marine Renewable Energy (PRIMaRE) and the Darwin Initiative. J.M.B. by a University of Exeter Research Studentship and the Darwin Initiative; P.C. by the Fundação para a Ciência e Tecnologia (FCT-Portugal) as part of the Programa Plurianual (UI\&D 331/94); M.S.C. by the Large Pelagics Research Centre at the University of New Hampshire through National Oceanographic and Atmospheric Agency award NA04NMF4550391; P.B.R. by the European Social Fund and Marine Conservation Society. The manuscript was improved by the comments of two anonymous referees.

\section{REFERENCES}

Amante, C. \& Eakins, B.W. (2008) ETOPO1 1 arc-minute global relief model: procedures, data sources and analysis. National Geophysical Data Center, NESDIS, NOAA, U.S. Department of Commerce, Boulder, CO. Available at: http://www.gfdl.noaa.gov/products/vis/data/datasets/

TerrainBase.html (accessed May 2008).

Andrews, R.D., Pitman, R.L. \& Ballance, L.T. (2008) Satellite tracking reveals distinct movement patterns for Type B and Type C killer whales in the southern Ross Sea, Antarctica. Polar Biology, 31, 1461-1468.

Balazs, G.H. (1980) Synopsis of biological data on the green turtle in the Hawaiian Islands. NOAA Technical Memorandum NMFS SWFC-7, Honolulu.

Balmford, A., Gravestock, P., Hockley, N., Mcclean, C.J. \& Roberts, C.M. (2004) The worldwide costs of marine protected areas. Proceedings of the National Academy of Sciences USA, 101, 9694-9697.

Bellwood, D.R., Hughes, T.P., Folke, C. \& Nystrom, M. (2004) Confronting the coral reef crisis. Nature, 429, 827-833.

Beyer, H.L. (2009) Geospatial modelling environment (version 0.5.3 beta). Available at: http://www.spatialecology.com (accessed March 2011).

Block, B.A., Costa, D.P., Boehlert, G.W. \& Kochevar, R.E. (2003) Revealing pelagic habitat use: the tagging of Pacific pelagics. Oceanologica Acta, 25, 255-266.

Blumenthal, J.M., Solomon, J.L., Bell, C.D., Austin, T.J., EbanksPetire, G., Coyne, M.S., Broderick, A.C. \& Godley, B.J. (2006) Satellite tracking highlights the need for international cooperation in marine turtle management. Endangered Species Research, 7, 1-11.

Boersma, P.D., Rebstock, G.A., Stokes, D.L. \& Majluf, P. (2007) Oceans apart: conservation models for two temperate penguin species shaped by the marine environment. Marine Ecology Progress Series, 335, 217-225.
Broderick, A.C., Frauenstein, R., Glen, F., Hays, G.C., Jackson, A.L., Pelembe, T., Ruxton, G.D. \& Godley, B.J. (2006) Are green turtles globally endangered? Global Ecology and Biogeography, 15, 21-26.

Broderick, A.C., Coyne, M.S., Fuller, W.J., Glen, F. \& Godley, B.J. (2007) Fidelity and over-wintering of sea turtles. Proceedings of the Royal Society B: Biological Sciences, 274, 1533-1538.

Brunnschweiler, J.M., Queiroz, N. \& Sims, D.W. (2010) Oceans apart? Short term movements and behaviour of adult bull sharks Carcharhinus leucas in Atlantic and Pacific oceans determined from pop off satellite archival tagging. Journal of Fish Biology, 77, 1343-1358.

Carr, A.F., Carr, M.H. \& Meylan, A.B. (1978) The ecology and migrations of sea turtles, 7 . The west Caribbean green turtle colony. Bulletin of the American Museum of Natural History, $162,1-46$.

Carr, M.H., Neigel, J.E., Estes, J.A., Andelman, S., Warner, R.R. \& Largier, J.L. (2003) Comparing marine and terrestrial ecosystems: implications for the design of coastal marine reserves. Ecological Applications, 13, 90-107.

Chaloupka, M., Bjorndal, K.A., Balazs, G.H., Bolten, A.B., Ehrhart, L.M., Limpus, C.J., Suganuma, H., Troëng, S. \& Yamaguchi, M. (2008) Encouraging outlook for recovery of a once severely exploited marine megaherbivore. Global Ecology and Biogeography, 17, 297-304.

Chape, S., Harrison, J., Spalding, M. \& Lysenko, I. (2005) Measuring the extent and effectiveness of protected areas as an indicator for meeting global biodiversity targets. Philosophical Transactions of the Royal Society B: Biological Sciences, 360, 443-455.

Cheng, I.J. (2000) Post-nesting migrations of green turtles (Chelonia mydas) at Wan-An Island, Penghu Archipelago, Taiwan. Marine Biology, 137, 747-754.

Coyne, M.S. \& Godley, B.J. (2005) Satellite tracking and analysis tool (STAT): an integrated system for archiving, analyzing and mapping animal tracking data. Marine Ecology Progress Series, 301, 1-7.

Crawley, M.J. (2007) The R book, 1st edn. John Wiley and Sons, Chichester.

Dewer, H., Thys, T., Teo, S.L.H., Farwell, C., O'Sullivan, J., Tobayama, T., Soichi, M., Nakatsubo, T., Konod, Y., Okada, Y., Lindsay, D.J., Hays, G.C., Walli, A., Weng, K., Streelamn, J.T. \& Karl, S.A. (2010) Satellite tracking the world's largest jelly predator, the ocean sunfish, Mola mola, in the Western Pacific. Journal of Experimental Marine Biology and Ecology, 393, 32-42.

Dobbs, K., Fernandes, L., Slegers, S., Jago, B., Thompson, L., Hall, J., Day, J., Cameron, D., Tanzer, J., MacDonald, F. \& Limpus, C. (2007) Incorporating marine turtle habitats into the marine protected area design for the Great Barrier Reef Marine Park, Queensland, Australia. Pacific Conservation Biology, 13, 293-302.

Dryden, J., Grech, A., Moloney, J. \& Hamann, M. (2008) Rezoning of the Great Barrier Reef World Heritage Area: does it afford greater protection for marine turtles? Wildlife Research, 35, 477-485. 
Eckert, K.L. \& Hemphill, A.H. (2005) Sea turtles as flagships for protection of the wider Caribbean region. Maritime Studies, 3-4, 119-143.

Edrén, S.M.C., Wisz, M.S., Teilmann, J., Dietz, R. \& Söderkvist, J. (2010) Modelling spatial patterns in harbour porpoise satellite telemetry data using maximum entropy. Ecography, 33, 698-708.

FAO (1990) Handbook of fishery statistical standards. Fishing areas for statistical purposes. FIGIS ontology sheets. FAO, Rome. Available at: http://www.fao.org/fishery/cwp/handbook/H (accessed June 2008).

Godley, B.J., Lima, E.H.S.M., Akesson, S., Broderick, A.C., Glen, F., Godfrey, M.H., Luschi, P. \& Hays, G.C. (2003) Movement patterns of green turtles in Brazilian coastal waters described by satellite tracking and flipper tagging. Marine Ecology Progress Series, 253, 279-288.

Godley, B.J., Blumenthal, J.M., Broderick, A.C., Coyne, M.S., Godfrey, M.H., Hawkes, L.A. \& Witt, M.J. (2008) Satellite tracking of sea turtles: where have we been and where do we go next? Endangered Species Research, 3, 3-22.

Godley, B.J., Barbosa, C., Bruford, M., Broderick, A.C., Catry, P., Coyne, M.S., Formia, A., Hays, G.C. \& Witt, M.J. (2010) Unravelling migratory connectivity in marine turtles using multiple methods. Journal of Applied Ecology, 47, 769-778.

Green, E. \& Short, F. (2003) World atlas of seagrasses (ed. by E.P. Green and F.T. Short). University of California Press, Berkeley, CA.

Halpern, B.S. (2003) The impact of marine reserves: do reserves work and does reserve size matter? Ecological Applications, 13, 117-137.

Halpern, B.S., Walbridge, S., Selkoe, K.A., Kappel, C.V., Micheli, F., D’Agrosa, C., Bruno, J.F., Casey, K.S., Ebert, C., Fox, H.E., Fujita, R., Heinemann, D., Lenihan, H.S., Madin, E.M.P., Perry, M.T., Selig, E.R., Spalding, M., Steneck, R. \& Watson, R. (2008) A global map of human impact on marine ecosystems. Science, 319, 948-952.

Hamann, M., Godfrey, M.H., Seminoff, J.A. et al. (2010) Global research priorities for sea turtles: informing management and conservation in the 21st century. Endangered Species Research, 11, 245-269.

Hays, G.C., Bradshaw, C.J.A., James, M.C., Lovell, P. \& Sims, D.W. (2007) Why do Argos satellite tags deployed on marine animals stop transmitting? Journal of Experimental Marine Biology and Ecology, 349, 52-60.

Hazel, J. (2009) Evaluation of fast-acquisition GPS in stationary tests and fine-scale tracking of green turtles. Journal of Experimental Marine Biology and Ecology, 374, 58-68.

Hooker, S.K. \& Gerber, L.R. (2004) Marine reserves as a tool for ecosystem-based management: the potential importance of megafauna. Bioscience, 54, 27-39.

IUCN (1994) Definitions and categories. Guidelines for applying protected areas management categories (ed. by N. Dudley), pp. 7-23. IUCN, Gland, Switzerland.

IUCN (2010) IUCN Red List of threatened species, version 2010.4. Available at: http://www.iucnredlist.org (accessed March 2011).
IUCN \& UNEP-WCMC (2010) The world database on Protected Areas (WDPA). Cambridge, UK. Available at: http:// www.protectedplanet.net (accessed March 2011).

Jackson, J.B.C. (1997) Reefs since Columbus. Coral Reefs, 16, S23-S32.

Jackson, J.B.C., Kirby, M.X., Berger, W.H., Bjorndal, K.A., Botsford, L.W., Bourque, B.J., Bradbury, R.H., Cooke, R., Erlandson, J., Estes, J.A., Hughes, T.P., Kidwell, S., Lange, C.B., Lenihan, H.S., Pandolfi, J.M., Peterson, C.H., Steneck, R.S., Tegner, M.J. \& Warner, R.R. (2001) Historical overfishing and the recent collapse of coastal ecosystems. Science, 293, 629-637.

Kennett, R., Munungurritj, N. \& Yunupingu, D. (2004) Migration patterns of marine turtles in the Gulf of Carpentaria, northern Australia: implications for Aboriginal management. Wildlife Research, 31, 241-248.

Koh, L.P., Dunn, R.R., Sodhi, N.S., Colwell, R.K., Proctor, H.C. \& Smith, V.S. (2004) Species coextinctions and the biodiversity crisis. Science, 305, 1632-1634.

Limpus, C.J., Miller, J.D., Paramenter, C.J., Reimer, D., McLachlan, N. \& Webb, R. (1992) Migration of green (Chelonia mydas) and loggerhead (Caretta caretta) turtles to and from eastern Australian rookeries. Wildlife Research, 19, 347357.

McClanahan, T.R., Marnane, M.J., Cinner, J.E. \& Kiene, W.E. (2006) A comparison of marine protected areas and alternative approaches to coral-reef management. Current Biology, 16, 1408-1413.

Marris, E. (2007) Conservation priorities: what to let go. Nature, 450, 152-155.

Paddack, M.J., Reynolds, J.D., Aguilar, C. et al. (2009) Recent region-wide declines in Caribbean reef fish abundance. Current Biology, 19, 590-595.

Pandolfi, J.M., Bradbury, R.H., Sala, E., Hughes, T.P., Bjorndal, K.A., Cooke, R.G., Mcardle, D., Mcclenachan, L., Newman, M.J.H., Paredes, G., Warner, R.R. \& Jackson, J.B.C. (2003) Global trajectories of the long-term decline of coral reef ecosystems. Science, 301, 955-958.

Pauly, D. \& Watson, R. (2005) Background and interpretation of the 'marine trophic index' as a measure of biodiversity. Philosophical Transactions of the Royal Society B: Biological Sciences, 360, 415-423.

Pauly, D., Christensen, V., Dalsgaard, J., Froese, R. \& Torres, F., Jr (1998) Fishing down marine food webs. Science, 279, 860863.

Pimm, S.L., Russell, G.J., Gittleman, J.L. \& Brooks, T.M. (1995) The future of biodiversity. Science, 269, 347-350.

R Development Core Team (2009) R: a language and environment for statistical computing. R Foundation for Statistical Computing, Vienna, Austria. ISBN 3-900051-07-0. Available at: http://www.R-project.org (accessed March 2011).

Rees, A.F., Jony, M., Margaritoulis, D. \& Godley, B.J. (2008) Satellite tracking of a green turtle Chelonia mydas from Syria further highlights importance of North Africa for Mediterranean turtles. Zoology in the Middle East, 45, 49-54.

Roberts, C.M., Branch, G., Bustamante, R.H., Castilla, J.C., Dugan, J., Halpern, B.S., Lafferty, K.D., Leslie, H., Lubchenco, 
J., McArdle, D., Ruckelshaus, M. \& Warner, R.R. (2003) Application of ecological criteria in selecting marine reserves and developing reserve networks. Ecological Applications, 13, S215-S228.

Schmidt, J.V., Schmidt, C.L., Ozer, F., Ernst, R.E., Feldheim, K.A., Ashley, M.V. \& Levine, M. (2009) Low genetic differentiation across three major ocean populations of the whale shark, Rhincodon typus. PLoS ONE, 4, e4988.

Seminoff, J.A., Resendiz, A. \& Nichols, W.J. (2002) Home range of green turtles Chelonia mydas at a coastal foraging area in the Gulf of California, Mexico. Marine Ecology Progress Series, 242, 253-265.

Spring, S. (1999) Satellite telemetry and green turtles. Reef Research, 9, 6-7.

Troëng, S. \& Chaloupka, M. (2007) Variation in adult annual survival probability and remigration intervals of sea turtles. Marine Biology, 151, 1721-1730.

Troëng, S., Evans, D.R., Harrison, E. \& Lagueux, C.J. (2005) Migration of green turtles Chelonia mydas from Tortuguero, Costa Rica. Marine Biology, 148, 435-447.

Votier, S.C., Grecian, W.J., Patrick, S. \& Newton, J. (2011) Intercolony movements, at-sea behaviour and foraging in an immature seabird: results from GPS-PPT tracking, radiotracking and stable isotope analysis. Marine Biology, 158, 355362.

Waycott, M., Duarte, C.M., Carruthers, T.J.B., Orth, R.J., Dennison, W.C., Olyarnik, S., Calladine, A., Fourqurean, J.W., Heck, K.L., Jr, Hughes, A.R., Kendrick, G.A., Kenworthy, W.J., Short, F.T. \& Williams, S.L. (2009) Accelerating loss of seagrasses across the globe threatens coastal ecosystems. Proceedings of the National Academy of Sciences USA, 106, 1237712381.

Witt, M.J., Åkesson, S., Broderick, A.C., Coyne, M.S., Ellick, J., Formia, A., Hays, G.C., Luschi, P., Stroud, S. \& Godley, B.J. (2010) Assessing accuracy and utility of satellite-tracking data using Argos-linked Fastloc-GPS. Animal Behaviour, 80, 571581.

Woodroffe, R. \& Ginsberg, J.R. (1998) Edge effects and the extinction of populations inside protected areas. Science, 280, 2126-2128.

\section{SUPPORTING INFORMATION}

Additional Supporting Information may be found in the online version of this article:

Figure S1 Spatial footprints of populations.

Table S1 Green turtle satellite tracking data.

Table S2 Marine protected Areas containing turtles. Appendix S1 Supporting references.

As a service to our authors and readers, this journal provides supporting information supplied by the authors. Such materials are peer-reviewed and may be re-organized for online delivery, but are not copy-edited or typeset. Technical support issues arising from supporting information (other than missing files) should be addressed to the authors.

\section{BIOSKETCHES}

The work was co-ordinated by the Marine Turtle Research Group (http://www.seaturtle.org/mtrg/) a group of professional scientists and student volunteers dedicated to undertaking fundamental and applied research on marine turtles whilst supporting local capacity building and the environmental awareness efforts necessary for successful conservation. Staff were joined by an international group of collaborators.

Rebecca Scott conducted this research as part of her MSc in Biodiversity and Conservation at the University of Exeter's Centre for Ecology and Conservation (UK) under the supervision of Brendan Godley. Specialized statistical expertise was offered by David Hodgson, GIS advice by Matthew Witt and networking facilitated by Michael Coyne founder of http://www.seaturtle.org and the Satellite Tracking and Analysis Tool. All authors provided data and were involved in data analysis and writing of the manuscript.

Editor: Erica Fleishman 